\title{
MOTIF-MOTIF TENUN PANDAISIKEK SEBAGAI INTERPRETASI FALSAFAH ALAM TAKAMBANG JADI GURU
}

\author{
Jonson Handrian Ginting
}

\begin{abstract}
Abstrak
Kemampuan masyarakat Minangkabau menjadikan alam sebagai guru mempengaruhi corak dan motif tenun Pandaisikek. Lebih lanjut lagi keadaan ini mendorong corak tenun untuk sesuai dengan apa yang ada di dalam budayanya sehingga terinterpretasi secara simbolis pada motif-motif tenun tersebut. Dengan kata lain, simbol-simbol pada motif tenun itu memiliki maknamakna yang mengacu pada bentuk ide perilaku dan idealisme falsafah tersebut. Artikel ini mendeskripsikan beberapa motif tenun Pandaisikek. Motifmotif tenun tersebut adalah interpretasi masyarakat terhadap alam sebagai salah satu bentuk simbol pembelajaran kepada generasi selanjutnya. Kata kunci: motif, tenun, Pandaisikek, Minangkabau

Abstract

Minangkabau people have ability to interpretate nature for Pandaisikek woven patterns and motifs. Furthermore this situation encourages weaving pattern to match what is in the culture so interpretated symbolically on the woven motifs. In other words, the symbols on the woven motifs have meanings that refer to the idea of the shape and behavior of the philosophical idealism. This article describes some of the Pandaisikek woven motifs. The woven motifs are people interpretation ofnature as one of the symbols and learning materials to thenext generation. Keywords: motif, weaving, Pandaisikek, Minangkabau
\end{abstract}

\section{PENDAHULUAN}

Indonesia memiliki keanekaragaman jenis kerajinan rakyat, salah satunya adalah tenunan. Sumatera Barat merupakan satu dari sekian banyak daerah penghasil tenunan yang memiliki ciri khas tersendiri disetiap daerahnya, seperti songket Pandaisikek, songket Silungkang, tenun Balapak di Tanjung Sungayang, dan songket Kubang. ${ }^{1}$

Menurut Caroline Nyamai-Kisia (2010), kearifan lokal adalah sumber pengetahuan yang diselenggarakan dinamis, berkembang, dan diteruskan oleh

1 Wati, Vera. 2003. “Studi tentang Tenun Balapak Tanjung Sungayang di Batusangkar". Padang: Skripsi, Jurusan Kesejahteraan Keluarga Fakultas Teknik Universitas Negrri Padang. 
populasi tertentu yang terintegrasi dengan pemahaman mereka terhadap alam dan budaya sekitamya. ${ }^{2}$ Pandaisikek sebagai salah satu daerah daerah penghasil tenunan memiliki kearifan lokal yang dijadikan motif-motif tenun. Menurut perkiraan, Pandaisikek merupakan daerah penghasil tenunan yang utama baik untuk jenis tenunan adat maupun tenunan baru karena disini terlihat adanya kegatan mempelajari dan memproduksi tenun baik secara formal ataupun informal. (Nusyirwan. 1982, 16).

Minangkabau sebagai suku bangsa memiliki nilai-nilai dan norma hasil belajar dari alam. Pemakaian kata "alam" mengandung makna yang tidak terbatas. Alam bagi masyarakat Minangkabau bukan hanya sebagai tempat lahir dan tempat mati, tempat hidup dan berkembang, melainkan juga memiliki makna filosofis seperti pepatah "Alam Takambang Jadi Guru". Oleh karena itu, ajaran dan pandangan hidup masyarakat Minangkabau mengacu pada pepatah-petitih, pituah, mamangan, dan mengambil ungkapan dari bentuk, sifat, dan kehidupan alam (Navis: 1894, 59).

Menurut hasil observasi penulis, kemampuan masyarakat Minangkabau berguru pada alam memberi pengaruh yang sangat besar dalam kehidupan sosial budayanya. Hal ini dapat dilihat dari berbagai aspek yang ada di Minangkabau yang tertuang dalam petatah-petitih yang akhirnya akan tercermin pada aktivitas, sifat, dan perilaku masyarakat itu sendiri. Motif-motif tenun atau songket Pandasikek adalah salah satu hasil belajar dari alam yang berlangsung melalui sosialisasi ataupun enkulturasi. Dengan kata lain, belajar dari alam merupakan sumber inspirasi untuk mewujudkan kearifan lokal.

Motif-motif tenun Pandaisikek sebagai kearifan lokal yang bersumber dari alam membutuhkan pengakuan sebagai jati diri. Pengakuan tersebut terbentuk dari hasil interaksi masyarakat yang ada di luar daerah atau di luar budayanya. Interaksi ini secara tidak langsung akan menjadi wadah sehingga budaya lain akan memberikan pengakuan terhadap budayanya.

Salah satu bentuk pengakuan pemerintah terhadap aktifitas menenun di Pandaisikek diabadikan pada pecahan uang Rp5000,00. Pemerintah mengakui keberadaan motif dan aktifitas menenun di Pandaisikek dan secara tidak langsung hal ini menunjukkan bahwa motif dan tenun masyarakat Pandaisikek adalah sebuah jati diri.

Motif-motif yang terdapat pada tenun Pandaisikek terwujud dalam bentuk sirnbol simbol yang perlu ditafsirkan. Makna-makna yang ada pada simbbol itu mengandung nilai ideal hasil belajar dari alam. Nilai-nilai inilah yang perlu dijaga dan direvitalisasi agar masyarakat luar tetap memberi pengakuan dan tetap menjadi salah satu ciri khas Sumatra Barat.

Penulis telah melakukan observasi dan wawancara terbuka dengan 13 orang mahasiswa Universitas Andalas dari berbagai fakultas dan jurusan yang berasal dari Pandaisikek. Hasilnya, hanya 4 orang saja yang bisa menenun dan mengetahui

2 Jendela Dunia Psikologi. [2012]. Pengertian Kearifan Lokal. [Online]. Tersedia:

http://www.psychologymania.com!2012!11/ pengertian-kearifan-lokal.html[14 September2013] 
nama beserta makna motifnya tenun Pandaisikek.

Perlu rasanya mengangkatkan kembali nilai-nilai yang terkandung dalam motif-motif tenun Pandaisikek agar bukan hanya eksistensi tenunnya saja yang terjaga melainkan juga aplikasi dari nilai-nilai yang terkandung di dalamnya.

Falsafah Alam Takambang Jadi Guru sebagai prinsip hidup masyarat Minangkabau memiliki peranan yang penting dalam mempengaruhi ide, perilaku, dan respons terhadap sesuatu. Sebagai pedoman hidup, falsafah ini bukan hanya mengatur kehidupan masyarakat tetapi sekaligus menjadi jati diri masyarakat itu sendiri. Kemampuan masyarakat Minangkabau menjadikan alam sebagai guru mempengaruhi corak dan motif tenun Pandaisikek. Lebih lanjut lagi keadaan ini mendorong corak tenun untuk sesuai dengan apa yang ada di dalam budayanya sehingga terinterpretasi secara simbolis pada motif-motif tenun tersebut. Dengan kata lain, simbol-simbol pada motif tenun itu memiliki makna-makna yang mengacu pada bentuk ide perilaku dan idealisme falsafah tersebut.

\section{KERANGKA TEORETIS}

Adat dan budaya Minangkabau sedikit banyak dipengaruhi oleh apa yang tampak dari alam. Dalam hal ini falsafah dan alam tidak bisa dipisahkan satu sama lain. Dengan kata lain, berguru kepada alam merupakan inspirasi terbesar dalam mengatur nilai-nilai ideal Minangkabau. Hal ini bisa dibuktikan dari pepatah petitih Minangkabau itu sendiri seperti panakiak pisau sirauit, ambiak galah batang lintabuang, salodang ambiak ka nyiru, nan satitiak jadikan lauik, nan sakapa jadikan gunuang, alam takambang jadikan guru.

Maka dengan menjadikan alam sebagai falsafah hidup, secara tidak langsung seluruh nilai dan norma yang ada di setiap pranata akan dipengaruhi. Seperti halnya pengetahuan alam dan lain-lain. Hal itu seperti pepatah berikut ingek-ingek sabalun kanai, nan di bawah kok mahimpik, gabak di hulu tando ka hujan, cewang di langik lando ka paneh. Pepatah-petitih di atas merupakan contoh kecil mengenai mawas diri dan kehati-hatian dalam bertindak yang dianalogikan melalui cuaca alam.

Sebagai sistem, konsep, dan motode yang digunakan secara selektif yaitu sebagai acuan oleh para penilik kebudayaan dalam menghadapi lingkungannya, maka kebudayaan berfungsi untuk menginterpretasikan lingkungan beserta isinya untuk pemenuhan kebutuhan-kebutuhan hidupnya sebagai manusia. Pemilihan secara selektif tersebut dilakukan berdasarkan pertimbangan oleh pelaku mengenai konsep, metode, ataupun teori yang mana yang tepat untuk digunakan sebagai acuan interpretasi dalam mewujudkan tindakan-tindakan. Tindakan-tindakan tersebut dapat dilihat sebagai dorongan dan motifasi dari dalam diri pelaku bagi pemenuhan kebutuhan ataupun sebagai tanggapan-tanggapan pelaku terhadap rangsangan-rangsangan yang ada di lingkungannya.

Kebudayaan pada dasarnya adalah sebuah pedoman yang dipakai oleh suatu masyarakat untuk memahami lingkungannya, baik lingkungan binaannya, dan lingk gan sosialnya. Pemahaman manusia terhadap lingkungannya mau tidak mau mendorong manusia untuk berfikir secara sistematis dan terbatas pada ruang 
dan:waktu (Rudito, 2006: 27).

Cara-cara pengamatan alam yang ditempuh manusia dalam proses belajar merupakan pengamatan secara sintetis, yaitu manusia rnemperhatikan gejala-gejala dalam situasi kongkret kejadian gejala itu. Pengetahuan dan perasaan si pengamat sendiri yang menentukan arti dari fenomena alam yang disaksikannya tetapi ia baru memberikan pendapatnya setelah menyelidiki faktor-faktor dan gejala-gejalanya. Proyek pengkajian nilai mengajukan suatu hipotesa pokok bahwa orientasi nilainilai memainkan peranan penting dalam bentuk pranata sosial dan mempengaruhi bentuk-bentuk tindakan sosial yang diamati. Yang dimaksud dengan orientasi nilainilai adalah makna pandangan-pandangan hidup dalam memberikan definisi arti kehidupan manusia dan memberikan wadah untuk menghadapi masalah-masalah di kemudian hari (Parsudi,1993: 161).

Sebagaimana dikemukakan di muka, nilai-nilai diwujudkan dalam kaidahkaidah yang mengatur kepentingan hidup pribadi maupun kepentingan hubungan antarmanusia. Kesemua kaidah tersebut disebut dengan etika atau lebih dikenal dengan sebutan moral. Ada beberapa petunjuk umum mengenai kreteria nilai yaitu:

1. Nilai terhadap hakikat hidup manusia.

2. Nilai terhadap karya dan hakikatnya

3. Nilai terhadap orientasi waktu dan kedudukan manusia dalam waktu tersebut

4. Nilai manusia terhadap lingkungan dan sekelilingnya

5. Nilai manusia terhadap lingkungan sosialnya .

Dari ke lima kriteria nilai tersebut, yang menjadi pokok pembahasan dalam artikel ini adalah nilai yang keempat yaitu nilai manusia terhadap lingkungan dan sekelilingnya.

Simbol merupakan penyatuan dua hal, yaitu objek dan makna yang kemudian luluh menjadi satu kesatuan. Jadi simbol akan memberitahu kita tentang sesuatu dimana pemberitahuan tersebut tidak seperti objek yang diwakilinya. ${ }^{3}$ Oleh karenanya, tingkah laku simbolik ini terkait dengan pengertian -pengertian yang ada dibalik tingkah laku yang tampak sehingga simbol-simbol yang ada di motif tenun Pandaisikek mengartikan segala tingkah laku yang terwujud dengan aturan yang ada di pranata sosialnya. Setelah negara, patokan dari terciptanya masyarakat multikultural adalah identitas budaya. Maka dari itu identitas merupakan suatu hal yang penting untuk setiap kebudayaan (Bouman, 1999: 19)

\section{MAKNA MOTIF-MOTIF TENUN PANDAI SIKEK}

Umumnya motif-motif tenun Pandaisikek yang berbentuk simbol diambil dari nama-nama hewan (fauna), nama-nama tumbuhan (flora), serta nama-nama benda lainnya yang memiliki makna tersendiri sesuai dengan interpretasi masyarakatnya. Dari inventarisasi Jasper dan Mas Pimgadie (dalam Nusyirwan A) mencatat terdapat 90 bentuk motif tenunan. Namun demikian, artikel ini hanya membahas motif yang dominan.

3 Bahan Kuliah Dr. Zainal Arifin M.Hum mata kuliah Teori Antropologi Modern 


\section{Itiak Pulang Patang}

Itik adalah sejenis unggas yang hidupnya di darat, pandai berenang, badannya seperti angsa tapi lebih kecil dan termasuk binatang peliharaan. Motif ini bercerita mengenai perilaku itik sewaktu pulang dan mencari makan yang selalu terlihat rapi dalam satu barisan yang terjaga keteraturannya. Motif ini memberi pesan bahwa solidaritas dalam kelompok harus tetap terjaga. Di samping itu, simbol ini menjelaskan bahwa masyarakat harus menaati pemimpin yang berdiri di depan agar kehidupan dalam berkelompok tetap harmonis. Perlu diketahui bahwa kawanan itik selalu digiring oleh itik jantan. Dengan kata lain, pemimpin barisan adalah itik jantan. Hal ini merupakan personifikasi dalam kehidupan masyarakat Minangkabau. Sistem kekerabatan Minangkabau menganut sistem matrilinial yaitu garis ibu, tetapi tanggung jawab sosial mengenai kehidupan dan keturunan adalah saudara laki-laki ibu atau lebih dikenal dengan sebutan mamak. Disamping itu, pemimpin di setiap suku adalah laki-laki yang disebut dengan penghulu.

\section{Cukia Bayam}

Bayam adalah tumbuhan sayuran yang bentuk daunnya bulat telur dengan ujung meruncing dan urat-uratnya terlihat jelas dan bunganya berbentuk malai yang tegak. Bayam adalah tumbuhan yang mudah sekali hidup hanya dengan menebarkan bijinya di sembarang.

Motif ini memberi pesan bahwa masyarakat Minangkabau khususnya Pandaisikek harus hidup seperti sifat bayam yang mudah hidup dan menyesuiakan diri di lingkungan sekitamya. Nilai-nilai ideal ini juga tertuang pada semboyan di mana bumi dipijak disitu langit dijunjung.

\section{Salapah Gadang Salapah Ketek}

Salapah adalah dompet kecil yang terbuat dari anyaman daun pandan dan kain. Dahulu, salapah ini dibawa ke mana saja oleh masyarakat Pandaisikek dan berisi siriah langkok. Bila bertemu, sebelum memulai perbincangan mereka akan membuka salapah dan menawarkannya kepada lawan bicaranya dan begitu juga sebaliknya. Motif ini mengajarkan kita bahwa selaku manusia kita harus saling berbagi apa yang kita punya kepada orang lain. Nilai inti yang dikandung dari simbol ini adalah solidaritas dan tenggang rasa yang harus dijunjung tinggi bersama seperti kata pepatah minang lamak dek awak katuju dek urang.

\section{Saik Kalamai}

Kalamai adalah makanan (sejenis dodol) yang bisa ditemui di daerah Minangkabau. Makanan ini biasanya ada pada acara-acara adat. Dalam bahasa indonesia saik berarti sayatan atau potongan. Kalamai terbuat dari dari tepung beras yang dicampur dengan gula dan kelapa. Proses pembuatannya cukup lama agar kental dan berminyak. Penyajiannya dipotong kecil berbentuk segi empat. Makna simbol dalam motif ini adalah hendaknya kita menanam sifat hemat dan tidak 
boros dalam diri kita, hal ini diafiliasikan dari cara makan gulamai yang sepotongsepotong. Sarna halnya yang termaktub dalam falsafah minang bakulimek sabalun habih ingek-ingek sabalun kanai.

\section{Pucuak Rabuang}

Pucuak rabuang merupakan anak bambu yang baru keluar dari umbinya. Bisa dijadikan makanan pelengkap saji dan biasanya dijadikan makanan adat pada acara-acara tertentu. Simbol dari motif ini mengajarkan kita agar hidup seperti sifat bambu yang sangat fungsional. Bambu saat masih muda bisa dijadikan untuk makanan. Ketika sudah besar menjadi bambu dapat dijadikan sebagai dinding rumah dan ketika tua dapat dijadikan sebagai tempat saluran air dan sebagainya. Dengan menganalogikan kehidupan bambu maka kita diharapkan agar bisa berguna untuk siapapun dari muda sampai tua.

\section{Saluak Laka}

Saluak adalah jalinan yang saling membanu dan laka adalah alas periuk yang terbuat dari lidi enau atau lidi kelapa. Jalinan lidi itu dibentuk bulat dan dapat dijadikan alas periuk. Motif ini memberikan kiasan bahwa jalinan kemasyarakatan yang kuat akan menjadikan kesatuan dan persatuan untuk memcapai tujuan bersama.

\section{Jariang Lawa}

Jariang lawa adalah sarang laba-laba. Sarang laba-laba biasaya berfungsi sebagai tinggal laba-laba serta sekaligus untuk perangkap mangsa. Sarang laba-laba terbuat dari bahan sutera yang keluar dari perut laba-laba. Hal ini mengajarkan kita untuk hidup secara mandiri dan tidak selalu bergantung pada orang lain dalam kehidupan layaknya laba-Iaba yang selalu berusaha sendiri dan mandiri.

\section{Barabah Mandi}

Barabah adalah hewan sejenis burung yang selalu bersuara dan memiliki kekhasan. Saat menemukan air, burung ini selalu mandi dengan menyelam dan langsung terbang kembali. Hal ini mengajarkan kita agar kita berfikir dahulu sebelum berbuat, apakah pekerjaan itu cocok dan dapat berguna. Di samping itu, kita diajarkan agar kerja tidak asal-asalan atau asal jadi sama seperti mandinya burung barabah.

\section{Balah Kacang}

Balah kacang artinya adalah belahan kacang. Kacang ketika direbus akan mudah tedepas dari kulitnya dan apabila direbus akan meletup-Ietup. Hal ini mengajarkan kita agar tidak lupa asal mula kita dan tidak seperti kacang meletup yang tidak memiliki tujuan dan dan arah dalam melakukan suatu pekerjaan. 


\section{Batang Padi}

Seperti yang kita ketahui bahwa padi semakin berisi (berbuah) akan semakin tambah merunduk. Inilah sifat yang perlu kita terapkan dalam kehidupan kita. Semakin ilmu kita bertambah maka kita tidak boleh menonjolkannya dengan sombong namun semakin tawadhu. Dengan sifat seperti ini memungkinkan orang akan menghargai dan lebih hormat kepada kita.

\section{Kunang-Kunang}

Kunang-kunang adalah binatang kecil yang saat malam hari akan bercahaya. Binatang ini tidak memberikan manfaat berupa materi dalam kehidupan mimusia sehari-hari tapi siapapun yang melihatnya akan terhibur. Pelajaran berharga yang perlu diambil dari kunang-kunang adalah hidup tidak melihat bentuk tubuh. Sekecil apapun hendaknya kita berguna untuk siapapun karena selain materi manusia bisa membantu melalui ilmu yang bisa bermanfaat untuk orang lain.

\section{Sirangkak}

Sirangkak adalah hewan sejenis kepiting yang hidup di air tawar dan di rawarawa. Sirangkak memiliki sepasang senjata pencapit untuk melumpuhkan mangsa. Walaupun jepitannya selalu terbuka tapi hewan ini tidak menjepit semua yang ditemuinya tapi kewaspadaan terhadap musuh yang diutamakannya. Namun kalau diganggu, hewan ini tidak segan-segan untuk menjepit apapun. Hal ini perIu kita terapkan dalam kehidupan sehari-hari bentuk dari ketegasan dan jati diri. Jangan pernah mencari masalah dengan orang lain, tetapi kalau orang menantang kita maka kita pantang mundur. Itulah tanda dari kehati-hatian dan kewaspadaan seperti yang terdapat dalam falsafah Minangkabau musuah indak dicari, basuo pantang dielakkan.

\section{PENUTUP}

Interpretasi budaya pada dasarnya adalah proses berjalannya pengetahuan seseorang yang terkait dengan kebudayaannya yang dipakai sebagai pedoman memahami lingkingan. Proses pengetahuan yang terwujud ini adalah tidak hanya berupa proses pemahaman terhadap kebudayaannya saja, akan tetapi menjadikan kebudayaannya terse but menjadi pendorong terwujudnya tingkah laku yang dalam hal ini berupa aturan-aturan dalam pranata sosial yang ada.

Alam takambang jadi guru sebagai falsafah tinggi alam Minangkabau sangat berperan dalam mempengaruhi motif-motif yang berupa simbol pada tenun Pandaisikek. Umumnya motif-motif tenun Pandaisikek yang berbentuk simbol diambil dari nama-nama hewan, nama-nama tumbuhan serta nama-nama benda lainnya yang memiliki makna tersendiri sesuai dengan interpretasi budaya masyarakatnya. Makna-makna yang ada pada sirnbol itu mengandung nilai-nilai luhur adat dan budaya Minangkabau. Nilai-nilai luhur yang ada pada adat dan budaya Minangkabau itu merupakan jati diri dari sukubangsa atau kebudayaan itu 
sendiri. Semakin besar upaya masyarakat minangkabau dalam mempertahankan nilai-nilai luhur itu dalam bentuk wujud apapun maka semakin jelas pula identitas suku bangsanya sebagai masyarakat multikultural.

\section{Daftar Pustaka}

Abdullah, Taufik. Manan, Imran dkk. 1999. Walk In Splendors: Ceremonial Drees and the Minangkabau. New York: University of California

Anwar, Adyan. (2009). Motif Tenun Pandaisikek. [Online]. Tersedia : http://www. angelfire.comJid/pusako/motif.htm. [2 oktober 2013]

Gunawan, Anggung. (2008). Bersandar Pada Alam Yang Nyata: Konsep Realis Falsafah Minangkabau. [Online]. Tersedia: http://grelovejogja.wordpress. comJ2008111/26lbersandar-pada-alam-yangnyatakonsep-realis-falsafahMinangkabaul [24 September 2013].

Boelaars, Y. 1984. Kepribadian Indonesia Modern: Suatu Penelitian Antropologi Budaya. Jakarta: PT Gramedia.

Boumann, Gerd. 1999. The Multucultural Riddle: Rethinking National, Ethnic and Religious Identities. London: Routledge.

Geertz, Clifford. 1992. Tafsir Kebudayaan. Y ogyakarta: Kanisius

Geerts, Hildred. 1981. Aneka Budaya dan Komunitas di Indonesia. Jakarta: Yayasan Ilmu Sosial \& FIS VI

Hakimy, H. Idrus. 1988. Rangkaian Mustika Adat Basandi Syarak di Minangkabau. Bandung: Remadja Karya

Jendela Dunia Psikologi. [2012]. Pengertian Kearifan Lokal. [Online]. Tersedia: http://www.psychologymania.coml20 12111 /pengertian-kearifan-Iokal. html [14

September 2013] .

Koentjaraningrat. 2001. Pengantar Antropologi 1. Jakarta: Rineka Cipta

Makmur, Erman, dkk. (1999). Kain Songket Pandai Sikek, Proyek PembinaanPermusiurnan Surnatera Barat. Padang.

M. Keesing, Roger. 1999. Antropolologi Budaya: Suatu Perspektif Kontemporer. Jakarta: Erlangga.

Meyliona, Geby. 2013. "Studi tentang tenunan Pandaisikek Di Rumah Tenun Pusako Kecamatan X koto Kabupaten Tanah Datar". Padang: Skripsi. Jurusan Kesejahteraan Keluarga Fakultas Teknik Universitas Negrri Padang.

Navis, AA. 1984. Alam Terkembang Jadi Guru: Adat dan Kebudayaan Minangkabau. Jakarta: GrafIti Pers

Nusyurwan, A. 1982. Ragam Hias Songket Minangkabau. Proyek Pembinaan Permesiuman Adityawarman Sumatra Parat, Padang.

Rohanah, Siti. 2005. Dinamika Usaha Kerajinan Kain Basurek di Bengkulu Tahun 19802000. Balai Kajian Sejarah dan Nilai Tradisional Padang.

Rudito, Bambang.2006. ApresiasiBudaya.Jakarta:Center ForSustianableDevelopment (ICSD)

Soekanto, Soerjono. 1992. Memperkenalkan Sosiologi. Jakarta:Rajawali Press.

Suparlan, Parsudi. 1993. Manusia, kebudayaan dan Lingkungannya. Jakarta: Rajawali Press.

Suparlan, Parsudi. 2004. Hubungan Antar Suku Bangsa. Jakarta: KIK Press.

Revantino. (2009). Pituah Rang Tuo Kito. [ online]. http://darevan. wordpress. com/2009/03116/pituah-rang-tuo-kito/ [24_2013L Tersedia: September

Taneko, Soleman B. 1994. Sisfem sosial Indonesia. Jakarta: Fajar Agung.

Wati, Vera. 2003. "Studi tentang Tenun Balapak Tanjung Sungayang di Batusangkar". Padang: Skripsi, Jurusan Kesejahteraan Keluarga Fakultas Teknik Universitas Negeri Padang . 